\title{
Review:
}

\section{Roles of SIRT3 in heart failure: from bench to bedside*}

\author{
De-xing $\mathrm{HU}^{\dagger 1,2,3}$, Xian-bao LIU ${ }^{1,2}$, Wen-chao $\mathrm{SONG}^{3}$, Jian-an $\mathrm{WANG}^{\dagger 1,2}$ \\ ( ${ }^{1}$ Department of Cardiology, the Second Affiliated Hospital, School of Medicine, Zhejiang University, Hangzhou 310009, China) \\ ( ${ }^{2}$ Provincial Key Laboratory of Cardiovascular Research of Zhejiang Province, Hangzhou 310009, China) \\ ( ${ }^{3}$ Department of Cardiology, Ningbo Medical Center Lihuili Eastern Hospital, Ningbo 315100, China) \\ †E-mail: 21318074@zju.edu.cn; jian_an_wang@yahoo.com \\ Received May 16, 2016; Revision accepted July 13, 2016; Crosschecked Oct. 18, 2016
}

\begin{abstract}
Heart failure (HF) represents the most common endpoint of most cardiovascular diseases (CVDs) which are the leading causes of death around the world. Despite the advances in treating CVDs, the prevalence of HF continues to increase. It is believed that better results of prognosis are obtained from prevention rather than additional treatment for HF. Therefore, it is reasonable to prevent the development of CVDs or other complications to HF. Most types of HF are attributed to contractile dysfunction, cardiac hypertrophy or remodeling, and ischemic injuries. SIRT3 is a mitochondrial nicotinamide adenine dinucleotide $\left(\mathrm{NAD}^{+}\right)$-dependent deacetylase whose substrates vary from metabolic biogenesis-associated proteins to stress-responsive proteins. In recent years, a number of studies have highlighted the cardio-protective role of SIRT3 and, as such, efforts have been made to induce over-expression or increased activity of this protein. In this review, we provide an overview of the roles of SIRT3 in cardiac hypertrophy induced by pressure overload or agonists and cardiomyocytes ischemic injuries. Moreover, we will introduce the application of SIRT3 agonists in the prevention of cardiac hypertrophy and ischemia reperfusion injury.
\end{abstract}

Key words: SIRT3, Heart failure, Hypertrophy, Ischemia reperfusion http://dx.doi.org/10.1631/jzus.B1600253

CLC number: R3

\section{Introduction}

Cardiovascular diseases (CVDs), which include hypertension, coronary heart diseases, valvular heart diseases, etc., are the most common causes of death around the word. According to the American Heart Association, CVDs have led to $32 \%$ of the deaths in United States since 1900, which is greater than cancer and chronic lower respiratory disease (CLRD) combined (Mozaffarian et al., 2016). Similar trends are observed in Europe, where CVDs are also the leading causes of death, and are responsible for half of all

\footnotetext{
${ }^{\ddagger}$ Corresponding author

* Project supported by the National Basic Research Program (973) of China (Nos. 2014CB965100, 2014CB965102, and 2014CB965103), the National High-Tech R \& D Program (863) of China (No. 2015AA020922), and the National Natural Science Foundation of China (Nos. 81320108003, 31371498, and 81570233)

(1) ORCID: De-xing HU, http://orcid.org/0000-0001-7586-5867; Jian-an WANG, http://orcid.org/0000-0003-0409-8941

(C) Zhejiang University and Springer-Verlag Berlin Heidelberg 2016
}

deaths each year (Townsend et al., 2015). As a result, heart failure (HF) is the common endpoint for most CVDs (Lüscher, 2015). Therapeutic strategies for HF emphasize normalization of hemodynamics and suppression of neurohumoral activation, which include pharmacological approaches, cardiac resynchronization therapy (CRT), certain disease management, and educational approaches (Yancy et al., 2013), but only CRT and certain disease management could improve the health-related quality of life (HRQOL) in HF (Schwer and Verdin, 2008; Lorenzen et al., 2012; Kober, 2016). However, it is believed that the prognosis can best be improved by prevention versus treatment for HF (Kober, 2016). Therefore, it is necessary to further characterize the mechanisms of pathogenesis and progression of HF to achieve additional benefits for patients.

Epigenetic modification has been demonstrated to play an important role in CVD (Lorenzen et al., 2012). Histone acetylation is an epigenetic modification, 
which is evolutionarily conserved from prokaryotes to eukaryotes (Schwer and Verdin, 2008; Finkel et al., 2009). This covalent modification is mediated by histone acetyltransferases such as Gen5/PCAF (general control nonderepressible-5/p300/cyclic adenosine monophosphate (cAMP)-response element binding protein binding protein (CBP)-associated factor) family and p300/CBP family, which can also acetylate non-histone proteins (Eckner, 1996; Lerin et al., 2006). Mammalian deacetylases are classified into four groups according to their phylogenic and sequence homology. Classes I, II, and IV deacetylases function as histone deacetylases and use zinc as a cofactor (Yang and Seto, 2007). Class III deacetylases, also defined as sirtuins, are $\mathrm{NAD}^{+}$-dependent enzymes. Accordingly, the dependency of their activity on $\mathrm{NAD}^{+}$indicates the links of sirtuins and energy or redox status. Sirtuins consist of seven members and play extensive roles in CVDs (Winnik et al., 2015). Notably, SIRT3 is the only sirtuin family member linked to longevity of human life (Rose et al., 2003; Bellizzi et al., 2005). The expression of SIRT3 is down-regulated in individuals over 60 years of age when compared to younger individuals, while endurance exercise leads to up-regulation of SIRT3 along with an improved health condition (Lanza et al., 2008). Given that CVD presents the most common pathology in individuals older than 60 years, these results suggest that SIRT3 may play an important cardioprotection role. In this review we will discuss the roles of SIRT3 in HF-associated complications and its prospective treatment implication.

\section{Epidemiology and pathophysiology of HF}

In the United States, more than 5 million individuals manifest HF with 870000 new cases diagnosed annually. Notably, the prevalence of HF continues to rise despite advancements in the prevention, diagnosis and treatment of CVDs (Mozaffarian et al., 2016). Hospital discharges of patients with a primary diagnosis of HF have continuously risen since 1975, and now represent more than 1 million patients discharged each year (Chen et al., 2011). In Europe, HF affects nearly $10 \%$ of men and $8 \%$ of women over the age of 60 years, with a prevalence that increases with age (Townsend et al., 2015). Two hypotheses have been proposed to explain this phenomenon. On one hand, disorders that lead to HF are not cured although the treatments of them have advanced, which leads to an increased number of patients living with HF. On the other hand, there is a large elderly population with various cardiovascular complications due to aging populations. Except for the CVDs, there are more and more age-associated chronic comorbid conditions with adverse cardiac consequences, which include type 2 diabetes mellitus, chronic obstructive pulmonary diseases, and chronic renal disease (Al-Ahmad et al., 2001; Kamalesh, 2007; Hannink et al., 2010). Therefore, it is reasonable to focus on the prevention and treatment of disorders responsible for HF.

In recent decades, considerable attention has been placed on elucidating the pathogenesis and progression of $\mathrm{HF}$ in a variety of models. The mechanisms are complex and proved to be interacted. Spann et al. (1967) investigated the intrinsic contractility of cardiac muscle in a cat HF model induced by pressure overload, and discovered a reduction in the force development of cardiac muscle isolated from the HF cats. This is the earliest study supporting the hemodynamic model, which lays the foundation for the pathophysiology of HF. In this hemodynamic model, it is believed that the heart fails to pump enough blood for the requirements of tissues during ordinary activity in the state of pathology induced by hemodynamic overload. Accompanied with hemodynamic overload is cardiac remodeling, which has been viewed as a characteristic pathological change during HF, caused by cell death, proliferation or hypertrophy of various cell types, and reconstruction of the extracellular matrix. In patients with HF with preserved ejection fraction (HFPEF), the left ventricular volume is normal but the wall is thickened and the myocardial stiffness is increased (Ohtani et al., 2012). However, in patients with HF with reduced ejection fraction (HFREF), the left ventricular is dilated and its thickness is either normal or reduced (Borbely et al., 2005). Notably, it has been demonstrated that the deletion of cardiomyocytes ultimately leads to HF (Olivetti et al., 1997). Nearly all types of HF are accompanied by increased cell death, attributed to stresses from circulating neurohormones, inflammation, oxidative stress, or toxins (Konstantinidis et al., 2012; Richter and Kostin, 2015). This leads to the release of growth factors which can result in the 
formation of fibrosis (Gandhi et al., 2011). In conjunction with cell death, remodeling of the extracellular matrix is also observed. Either inadequate fibrosis, which leads to thinning of the ventricular wall or increased synthesis of extracellular matrix, which enhances the ventricular stiffness, is believed to weaken their pumping function and contributes to HF (Katz and Zile, 2006). Another factor contributed to cardiac remodeling is inflammation. Immune activation and inflammation response occur in patients with $\mathrm{HF}$ and act as a double-edged sword. On one hand, it is an adaptive and reparative response to heart injury through scavenging the detrimental subjects and rebuilding the microenvironment by recruiting the inflammatory cells and secreting cytokines. On the other hand, overactivation of inflammation not only leads to the death or hypertrophy of cells comprising the heart tissue, but also results in excessive fibrosis (Briasoulis et al., 2016). The neurohumoral model of HF has drawn great attention from researchers in recent years, which causes effects on HF in many aspects. In the compensated period, the activation of the adrenergic nervous system and reninangiotensin-aldosterone system contributes to the increase of heart contractility and redistribution of blood. However, in the decompensated period, they lead to depressed contractility of the failing heart and increased blood pressure by causing maladaptive remodeling of the ventricular and vascular (Braunwald, 2013). More recently, cardiac genetic research has identified several important monogenic disorders or gene mutations of inherited cardiomyopathies that lead to HF (Morita et al., 2005; Herman et al., 2012; Towbin, 2014). In addition, the current investigations focused on searching for disease-associated genetic variants by scanning the entire genome using genome-wide-association-studies (Zeller et al., 2012). Despite these advances, our understanding of the pathogenesis of HF remains incomplete.

\section{Characteristics and functions of SIRT3}

To identify the biological function of a gene, it is necessary to resolve the protein structure and subcellular localization. Human SIRT3 protein includes a full length $(44 \mathrm{kD})$ and short length $(28 \mathrm{kD})$ form, which lacks the N-terminal 142 residues. Onyango et al. (2002) have analyzed the protein structure of full length SIRT3 using the bioinformatic methods, identifying six motifs within the protein. Two of these motifs were HTHLACI1 and PNDRDTASEI6, indicating that SIRT3 may possess enzymatic activities. Another two motifs were matched to GLUTRNSPORT, a glucose transporter signature. Other matches included a zinc finger motif, suggesting the potential interaction between SIRT3 and DNA, and protein or itself. They also observed that the expression of SIRT3 in metabolically active tissues such as liver, muscle, heart, and kidney was significantly elevated, indicating that SIRT3 may participate in metabolic homeostasis. They also identified that the N-terminus containing a mitochondrial localization signal was necessary for its localization. However, a controversial report argued that endogenous SIRT3 is located in the nucleus and translocates into mitochondria under cellular stress or following over-expression of SIRT3 (Scher et al., 2007). In the study of Sundaresan et al. (2008), full length SIRT3 localized to the mitochondria, nucleus, and cytoplasm, while the short form localized exclusively to the mitochondria of the mouse cardiomyocytes. These results were confirmed by recent studies (Chen et al., 2015b). The discrepancy is believed to be due to differences in cell types used between the studies and the stages of cell life when SIRT3 was detected.

SIRT3 is a soluble mitochondrial protein highly expressed in mitochondrial rich tissues and also plays critical roles related to tumor suppression, cellular stress, fat acid metabolism, oxidative stress response, and age-associated hearing loss (Hirschey et al., 2010; Kim et al., 2010; Someya et al., 2010). Lombard et al. (2007) found that no abnormalities were identified in SIRT3-deficient mice under non-stress conditions; however, the hyperacetylation of mitochondrial proteins was observed when stress was applied. Using a comprehensive multi-tissue quantitative acetylproteome analysis approach, Dittenhafer-Reed et al. (2015) identified 6286 acetylation sites, of which nearly 4000 were localized to mitochondrial proteins. They also conducted a biological pathway analysis to assess pathways regulated by SIRT3-mediated acetylation, revealing that fuel-producing and fuelutilizing tissues display unique SIRT3-dependent alterations and that SIRT3 is coupled to metabolic homeostasis. Despite these studies, most of the functions of SIRT3 remain to be investigated. 


\section{Role of SIRT3 in ameliorating cardiac hypertrophy}

Cardiac hypertrophy is an adaptive response to increased mechanical stress from physiological or pathological stimuli. Both intrinsic factors such as hypertrophic cardiomyopathy or ischemia-induced remodeling and extrinsic factors such as increased volume or pressure overload contribute to hypertrophy. In the period of compensated hypertrophy, there is no significant impact on the cardiac performance, but decompensated hypertrophy results in contractile dysfunction and HF.

The heart is the greatest oxygen consuming organ, needing a persistent supply of energy to drive circulation. Moreover, nearly all cellular processes of cardiomyocytes are driven by ATP-dependent pathways. As an energy producing organelle, the mitochondria encompasses about $1 / 3$ of the cellular volume in cardiomyocytes (Schaper et al., 1985). Mitochondrial fatty acid and glucose oxidation represent the major sources of ATP generation in healthy hearts (Bing et al., 1954; Taegtmeyer, 1994; Stanley and Chandler, 2002). Although increased mitochondrial respiratory activity is observed during the early stages of cardiac hypertrophy, the oxidative phosphorylation rate decreases upon progression to decompensated hypertrophy or HF (Lindenmayer et al., 1971; Sordahl et al., 1973). Mitochondrial SIRT3 is reported to play important roles in maintaining basal ATP levels and regulating energy production. Ahn et al. (2008) demonstrated a $>50 \%$ decline of basal ATP levels with concomitant hyperacetylation of mitochondrial proteins in $\mathrm{SIRT}^{-/-}$mice, while reconstitution with wild-type SIRT3 restored ATP levels in mouse embryonic fibrioblasts. Smith et al. (2011) further analyzed the deacetylation activity of SIRT3 using peptide arrays and machine learning. They confirmed a variety of potential SIRT3 substrates which participate in ATP synthesis, fatty acid oxidation, and the urea cycle. In the recent studies from Chen et al. (2015b) and Koentges et al. (2015), SIRT3 is reported to attenuate cardiac hypertrophy and dysfunction induced by transverse aortic constriction (TAC) by regulating the acetylation of mitochondrial proteins. Chen et al. (2015b) demonstrated that the short form of SIRT3 was downregulated in the hypertrophic heart accompanied by higher levels of acetylation of long-chain acetyl-CoA dehydrogenase (LCAD) which participates in fatty acid oxidation. Moreover, SIRT3-KO mice exhibited severer hypertrophy and increased accumulation of lipids. Upon SIRT3 over-expression in cardiomyocytes, lipid accumulation was attenuated through the deacetylation of LCAD. In support of these findings, Koentges et al. (2015) identified a decrease of cardiac function in the working heart isolated from SIRT3KO mice. Oxidation of palmitate and glucose was decreased, while the rates of glycolysis increased. In addition, they identified hyperacetylation of $84 \mathrm{mi}-$ tochondrial proteins including enzymes related to fatty acid transport and oxidation, subunits of the electron transport chain and enzymes involved in the tricarboxylic acid cycle. In Angiotension II-induced cardiac hypertrophy, the protective effect of SIRT3 was also observed through increasing the NAD level by interacting and deacetylating nicotinamide mononucleotide adenylyltransferase 3 (NMNAT3), the rate-limiting enzyme for mitochondrial NAD biosynthesis (Yue et al., 2016). These results suggest that SIRT3 participates in the mitochondrial metabolism and energy production of the heart, which is associated with the maintenance of the cardiac function.

Reactive oxygen species (ROS) are normal mitochondrial metabolic products involved in energy production, which have been shown to contribute to the development of cardiac hypertrophy (Cole et al., 2006, van Empel et al., 2006). A variety of hypertrophic pathways activated by ROS have been identified, including mitogen-activated protein kinase (MAPK), extracellular signal-regulated kinase 1/2 (ERK1/2), protein kinase C (PKC), c-Jun N-terminal kinase (JNK), phosphoinositide-3 kinase (PI3K), protein kinase $\mathrm{B}(\mathrm{PKB})$, and nuclear factor- $\mathrm{\kappa B}$ (NF-kB) (Li et al., 2006; Wenzel et al., 2007; Adiga and Nair, 2008; Zhang et al., 2008; Zou et al., 2008; Cai et al., 2009; Guo et al., 2009). Interestingly, inhibition of ROS by antioxidants is believed to block cardiac hypertrophy induced by angiotensin II ( $\mathrm{Hu}$ et al., 2006). There are two cellular mechanisms used to counteract ROS, which include: (1) antioxidant enzymes such as superoxide dismutase (SOD), catalase, and peroxidases, and (2) reductant species such as glutathione and thioredoxin (Berndt et al., 2007). Manganese SOD and catalase are enhanced by the forkhead transcription factor box $\mathrm{O}$ family (FoxOs) 
(Daitoku et al., 2004; Tan et al., 2008) which could be regulated by SIRT3 deacetylase activity (Tseng et al., 2013). Intriguingly, SIRT3 has been proven to ameliorate the cardiac hypertrophy by eliminating ROS through deacetylation and activating FoxO3a (Sundaresan et al., 2009).

In addition to the mechanisms mentioned above, several disputable or potential explanations have also been suggested in recent years. Zeng et al. (2015) found that mice fed with high-fat-diet (HFD) showed cardiac hypertrophy and dysfunction with reduced capillary density, increased ROS production, and impaired HIF signaling. In this context, SIRT3 was down-regulated by HFD. SIRT3-KO mice showed similar but more severe phenotypes with HFD mice, while the capillary density in the SIRT3-KO mice was not further reduced by HFD. These results indicate that SIRT3 may play an important role in preserving cardiac function and capillary density in the HFDinduced obesity, but the mechanisms involved remain to be further clarified. In another study, Hafner et al. (2010) found that SIRT3 deficient mice showed cardiac hypertrophy and fibrosis accompanied by increased opening of the mitochondrial permeability transition pore (mPTP) and mitochondrial swelling at 13 months of age. They also observed that SIRT3 could deacetylate cyclophilin $\mathrm{D}$, a component of mPTP, on lysine 166, which led to inhibition of the mPTP opening. From these data, they suggested that SIRT3 could prevent age-related mitochondrial dysfunction and cardiac hypertrophy.

\section{Role of SIRT3 in attenuating ischemia and/or reperfusion-induced injury}

Ischemic heart disease, which is triggered by temporary or permanent blockage of the coronary blood flow, can result in heart disability or even sudden death. Furthermore, most patients with myocardial infarction (MI) will develop into HF. Despite the advancement in therapy for MI, chronic HF induced by MI remains the chief cause of mortality (Velagaleti et al., 2008; Hung et al., 2013; Greco et al., 2015). Thus, improving the therapeutic effect for MI or preventing the progression to HF remains a critical concern. Early reperfusion is believed to be the most effective therapy to reduce myocardial damage induced by ischemia and hypoxia (Zhang and Huo, 2011), but the benefits of blood restoration are soon attenuated by reperfusion injury (Piper et al., 1998). Although some strategies, such as postconditioning, have been put forward to ameliorate the reperfusion injury, the incidences of total major cardiac events were not decreased (Hu et al., 2014). Several mechanisms have been discovered, including calcium overload, increased ROS formation, autophagy, apoptosis, and mitochondrial dysfunction (Murphy and Steenbergen, 2008; Marzetti et al., 2013). Intriguingly, these mechanisms interacted with each other. As such, it is a challenge to achieve and overcome the negative complications associated with the management of ischemia reperfusion.

Fortunately, SIRT3 has been demonstrated to participate in numerous biological processes including anti-oxidation reactions, cell survival, and mitochondrial protection, all of which could contribute to the treatment of ischemic heart disease (Kim et al., 2010; Someya et al., 2010; Dittenhafer-Reed et al., 2015). Since loss of cardiomyocytes due to cell death is the main cause of cardiac dysfunction following MI, inhibition of apoptosis or necrosis is a critical necessity. It has been shown that SIRT3 is able to protect cardiomyocytes from apoptosis induced by genotoxic and oxidative stress through an extra-mitochondrial pathway by deacetylating Ku-70 (Sundaresan et al., 2008). Sundaresan et al. (2008) examined the cell survival by subjecting cardiomyocytes to the stress of $N$-methyl- $N$ '-nitro- $N$-nitrosoguanidine (MNNG) or $\mathrm{H}_{2} \mathrm{O}_{2}$. They observed a reduction of apoptosis mediated by Bax which is hindered by $\mathrm{Ku}-70$ binding, and confirmed that increased binding of $\mathrm{Bax}$ and $\mathrm{Ku}-70$ is due to the deacetylation of Ku-70 by SIRT3. Chen et al. (2013) pointed out that NF-kB represents another target of SIRT3, which is responsible for the survival of cardiomyocytes exposed to $\mathrm{H}_{2} \mathrm{O}_{2}$. They found that SIRT3 was down-regulated by oxidative stress in $\mathrm{H} 9 \mathrm{C} 2$ cardiomyocytes and treatment with resveratrol reversed the stress-induced expression changes. Over-expression of SIRT3 induces NF- $\mathrm{kB}$ to exit the nucleus and alter the expression of apoptosis-related genes, Bcl-2 and Bax. As mentioned above, SIRT3 is able to deacetylate the mPTP component CyPD and inhibit its opening. Bochaton et al. (2015) confirmed that SIRT3 was also necessary for the prevention of reperfusion injury via a mechanism 
which is similar to that observed with the inhibition of mPTP opening by CyPD. Thus, while SIRT3 plays an important role in protecting cardiomyocytes from oxidative or ischemia reperfusion injury in vitro, it remains to be determined if the same effects can be seen in vivo.

\section{Application perspectives}

As a member of sirtuins, SIRT3 functions as a deacetylase that takes part in various cellular processes, including cell growth and survival, apoptosis, senescence, metabolism, and mitochondrial integrity. Even though the deacetylase activity of SIRT3 has been confirmed and thousands of substrates have been detected using multi-tissue quantitative proteomics, bioinformatic analysis, and biochemical validation (Schaper et al., 1985; Taegtmeyer, 1994), few functions have been performed, particularly as they relate to heart diseases. In this context, we have discussed the protective roles of SIRT3 in cardiac hypertrophy and ischemia reperfusion or oxidative stress-induced cell death which are the chief causes of HF. Otherwise, there remains a quantity of questions to be answered regarding the cardioprotective role of SIRT3, considering that most substrates localized in mitochondria are required to be investigated (Verdejo et al., 2012). For instance, SIRT3 has been demonstrated to activate peroxisome proliferator-activated receptor $\gamma$ coactivator $1-\alpha$ (PGC-1 $\alpha$ ), which takes part in mitochondrial biogenesis, but the role of SIRT3 in mitochondrial biogenesis and its association with cardiac hypertrophy remain to be clarified. Moreover, the effects of SIRT3 on HF induced by metabolic disorders such as type 2 diabetes also need to be investigated for its regulatory function in metabolism.

Recently, several pharmacological agents have been discovered that can lead to activation of SIRT3 and cardioprotection. Resveratrol is the first compound to be demonstrated to activate sirtuins and it is broadly investigated in CVD as a SIRT1 agonist; however, there have been few publications regarding its role in activating SIRT3. Chen et al. (2015a) recently confirmed that resveratrol could activate SIRT3, then prevent cardiac hypertrophy, and ameliorate the cardiac fibrosis through inhibiting the transforming growth factor (TGF)- $\beta / \mathrm{Smad} 3$ pathway.
The mechanisms are proved to be that activation of SIRT3 by resveratrol down-regulates TGF- $\beta$ and brings about dephosphorylation of the Smad3, which leads to the down-regulation of plasminogen activator inhibitor-1 (PAI-1) and decreased activities of plasmin-dependent matrix metalloproteinases. In addition, Pillai et al. (2015) have identified the protective effects of Honokiol and demonstrated this agent prevented cardiac hypertrophic responses and attenuated pre-existing cardiac hypertrophy via SIRT3 activation. Losartan is an angiotensin II type I receptor blocker that was introduced as an antihypotension medicine. Klishadi et al. (2015) demonstrated that it exerted protective effects in ischemia reperfusion injuries by normalizing the protein level of SIRT3 and up-regulating the pro-survival factors in ischemic heart. Recently, another molecular Adjudin, which was developed as an anti-spermatogenic agent, was proved to directly activate mitochondrial-located SIRT3 in hair cells of the cochlea (Xia and Geng, 2016). Its role in cardiac cells was expected. Therefore, the pharmacological intervention for SIRT3 activity has emerged, which sheds light on its clinical applications.

In conclusion, SIRT3 exerts various benefits in cardiac hypertrophy and ischemic heart disease, and may represent a novel therapeutic target of addressing $\mathrm{HF}$ in the near future.

\section{Compliance with ethics guidelines}

De-xing HU, Xian-bao LIU, Wen-chao SONG, and Jian-an WANG declare that they have no conflict of interest.

This article does not contain any studies with human or animal subjects performed by any of the authors.

\section{References}

Adiga, I.K., Nair, R.R., 2008. Multiple signaling pathways coordinately mediate reactive oxygen species dependent cardiomyocyte hypertrophy. Cell Biochem. Funct., 26(3): 346-351. http://dx.doi.org/10.1002/cbf.1449.

Ahn, B.H., Kim, H.S., Song, S., et al., 2008. A role for the mitochondrial deacetylase Sirt3 in regulating energy homeostasis. PNAS, 105(38): 14447-14452. http://dx.doi.org/10.1073/pnas.0803790105

Al-Ahmad, A., Sarnak, M.J., Salem, D.N., 2001. Cause and management of heart failure in patients with chronic renal disease. Semin. Nephrol., 21(1):3-12.

Bellizzi, D., Rose, G., Cavalcante, P., et al., 2005. A novel VNTR enhancer within the SIRT3 gene, a human homologue of $S I R 2$, is associated with survival at oldest 
ages. Genomics, $\mathbf{8 5}(2)$ :258-263.

http://dx.doi.org/10.1016/j.ygeno.2004.11.003

Berndt, C., Lillig, C.H., Holmgren, A., 2007. Thiol-based mechanisms of the thioredoxin and glutaredoxin systems: implications for diseases in the cardiovascular system. Am. J. Physiol. Heart Circ. Physiol., 292(3):H1227-H1236. http://dx.doi.org/10.1152/ajpheart.01162.2006

Bing, R.J., Siegel, A., Ungar, I., et al., 1954. Metabolism of the human heart. II. Studies on fat, ketone and amino acid metabolism. Am. J. Med., 16(4):504-515. http://dx.doi.org/10.1016/0002-9343(54)90365-4

Bochaton, T., Crola-Da-Silva, C., Pillot, B., et al., 2015. Inhibition of myocardial reperfusion injury by ischemic postconditioning requires sirtuin 3-mediated deacetylation of cyclophilin D. J. Mol. Cell. Cardiol., 84:61-69. http://dx.doi.org/10.1016/j.yjmcc.2015.03.017

Borbely, A., van der Velden, J., Papp, Z., et al., 2005. Cardiomyocyte stiffness in diastolic heart failure. Circulation, 111(6):774-781. http://dx.doi.org/10.1161/01.CIR.0000155257.33485.6D

Braunwald, E., 2013. Heart failure. JACC Heart Fail, 1(1): $1-20$. http://dx.doi.org/10.1016/j.jchf.2012.10.002

Briasoulis, A., Androulakis, E., Christophides, T., et al., 2016. The role of inflammation and cell death in the pathogenesis, progression and treatment of heart failure. Heart Fail Rev., 21(2):169-176. http://dx.doi.org/10.1007/s10741-016-9533-z

Cai, J., Yi, F.F., Bian, Z.Y., et al., 2009. Crocetin protects against cardiac hypertrophy by blocking MEK-ERK1/2 signalling pathway. J. Cell. Mol. Med., 13(5):909-925. http://dx.doi.org/10.1111/j.1582-4934.2008.00620.x

Chen, C.J., Fu, Y.C., Yu, W., et al., 2013. SIRT3 protects cardiomyocytes from oxidative stress-mediated cell death by activating NF-kB. Biochem. Biophys. Res. Commun., 430(2): 798-803. http://dx.doi.org/10.1016/j.bbrc.2012.11.066

Chen, J., Normand, S.L., Wang, Y., et al., 2011. National and regional trends in heart failure hospitalization and mortality rates for medicare beneficiaries, 1998-2008. JAMA, 306(15):1669-1678. http://dx.doi.org/10.1001/jama.2011.1474

Chen, T., Li, J., Liu, J., et al., 2015a. Activation of SIRT3 by resveratrol ameliorates cardiac fibrosis and improves cardiac function via the TGF- $\beta / \mathrm{Smad} 3$ pathway. Am. $J$. Physiol. Heart Circ. Physiol., 308(5):H424-H434. http://dx.doi.org/10.1152/ajpheart.00454.2014

Chen, T., Liu, J., Li, N., et al., 2015b. Mouse SIRT3 attenuates hypertrophy-related lipid accumulation in the heart through the deacetylation of LCAD. PLOS ONE, 10(3): e0118909. http://dx.doi.org/10.1371/journal.pone.0118909

Cole, M.P., Chaiswing, L., Oberley, T.D., et al., 2006. The protective roles of nitric oxide and superoxide dismutase in adriamycin-induced cardiotoxicity. Cardiovasc. Res., 69(1):186-197. http://dx.doi.org/10.1016/j.cardiores.2005.07.012

Daitoku, H., Hatta, M., Matsuzaki, H., et al., 2004. Silent information regulator 2 potentiates Foxo1-mediated transcription through its deacetylase activity. PNAS, 101(27):10042-10047. http://dx.doi.org/10.1073/pnas.0400593101

Dittenhafer-Reed, K.E., Richards, A.L., Fan, J., et al., 2015. SIRT3 mediates multi-tissue coupling for metabolic fuel switching. Cell Metab., 21(4):637-646. http://dx.doi.org/10.1016/j.cmet.2015.03.007

Eckner, R., 1996. p300 and CBP as transcriptional regulators and targets of oncogenic events. Biol. Chem., 377(11): 685-688.

Finkel, T., Deng, C.X., Mostoslavsky, R., 2009. Recent progress in the biology and physiology of sirtuins. Nature, 460(7255):587-591.

http://dx.doi.org/10.1038/nature08197

Gandhi, M.S., Kamalov, G., Shahbaz, A.U., et al., 2011. Cellular and molecular pathways to myocardial necrosis and replacement fibrosis. Heart Fail. Rev., 16(1):23-34. http://dx.doi.org/10.1007/s10741-010-9169-3

Greco, C., Rosato, S., D'Errigo, P., et al., 2015. Trends in mortality and heart failure after acute myocardial infarction in Italy from 2001 to 2011. Int. J. Cardiol., 184:115-121. http://dx.doi.org/10.1016/j.ijcard.2015.01.073

Guo, J., Gertsberg, Z., Ozgen, N., et al., 2009. p66Shc links $\alpha_{1}$-adrenergic receptors to a reactive oxygen speciesdependent AKT-FOXO3A phosphorylation pathway in cardiomyocytes. Circ. Res., 104(5):660-669. http://dx.doi.org/10.1161/CIRCRESAHA.108.186288

Hafner, A.V., Dai, J., Gomes, A.P., et al., 2010. Regulation of the MPTP by SIRT3-mediated deacetylation of CypD at lysine 166 suppresses age-related cardiac hypertrophy. Aging (Albany NY), 2(12):914-923. http://dx.doi.org/10.18632/aging.100252

Hannink, J.D., van Helvoort, H.A., Dekhuijzen, P.N., et al., 2010. Heart failure and COPD: partners in crime? Respirology, 15(6):895-901. http://dx.doi.org/10.1111/j.1440-1843.2010.01776.x

Herman, D.S., Lam, L., Taylor, M.R., et al., 2012. Truncations of titin causing dilated cardiomyopathy. N. Engl. J. Med., 366(7):619-628. http://dx.doi.org/10.1056/NEJMoa1110186

Hirschey, M.D., Shimazu, T., Goetzman, E., et al., 2010. SIRT3 regulates mitochondrial fatty-acid oxidation by reversible enzyme deacetylation. Nature, 464(7285): 121-125. http://dx.doi.org/10.1038/nature08778

Hu, T.P., Xu, F.P., Li, Y.J., et al., 2006. Simvastatin inhibits leptin-induced hypertrophy in cultured neonatal rat cardiomyocytes. Acta Pharmacol. Sin., 27(4):419-422. http://dx.doi.org/10.1111/j.1745-7254.2006.00300.x

Hu, X.Q., Cheng, J., Tang, B., et al., 2014. Clinical effect of postconditioning in ST-elevation myocardial infarction patients treated with primary percutaneous coronary 
intervention: a meta-analysis of randomized controlled trials. J. Zhejiang Univ.-Sci. B (Biomed. \& Biotechnol.), 12(8):629-632. http://dx.doi.org/10.1631/jzus.B1101010

Hung, J., Teng, T.H., Finn, J., et al., 2013. Trends from 1996 to 2007 in incidence and mortality outcomes of heart failure after acute myocardial infarction: a population-based study of 20812 patients with first acute myocardial infarction in Western Australia. J. Am. Heart Assoc., 2(5): e000172. http://dx.doi.org/10.1161/JAHA.113.000172

Kamalesh, M., 2007. Heart failure in diabetes and related conditions. J. Card. Fail., 13(10):861-873. http://dx.doi.org/10.1016/j.cardfail.2007.07.007

Katz, A.M., Zile, M.R., 2006. New molecular mechanism in diastolic heart failure. Circulation, 113(16):1922-1925. http://dx.doi.org/10.1161/circulationaha.106.620765

Kim, H.S., Patel, K., Muldoon-Jacobs, K., et al., 2010. SIRT3 is a mitochondria-localized tumor suppressor required for maintenance of mitochondrial integrity and metabolism during stress. Cancer Cell, 17(1):41-52. http://dx.doi.org/10.1016/j.ccr.2009.11.023

Klishadi, M.S., Zarei, F., Hejazian, S.H., et al., 2015. Losartan protects the heart against ischemia reperfusion injury: sirtuin3 involvement. J. Pharm. Pharm. Sci., 18(1):112-123. http://dx.doi.org/10.18433/J3XG7T

Kober, L., 2016. Heart failure in 2015: better results from prevention than from additional treatment. Nat. Rev. Cardiol., 13(2):75-77. http://dx.doi.org/10.1038/nrcardio.2015.205

Koentges, C., Pfeil, K., Schnick, T., et al., 2015. SIRT3 deficiency impairs mitochondrial and contractile function in the heart. Basic Res. Cardiol., 110(4):36. http://dx.doi.org/10.1007/s00395-015-0493-6

Konstantinidis, K., Whelan, R.S., Kitsis, R.N., 2012. Mechanisms of cell death in heart disease. Arterioscler. Thromb. Vasc. Biol., 32(7):1552-1562. http://dx.doi.org/10.1161/ATVBAHA.111.224915

Lanza, I.R., Short, D.K., Short, K.R., et al., 2008. Endurance exercise as a countermeasure for aging. Diabetes, 57(11): 2933-2942. http://dx.doi.org/10.2337/db08-0349

Lerin, C., Rodgers, J.T., Kalume, D.E., et al., 2006. GCN5 acetyltransferase complex controls glucose metabolism through transcriptional repression of PGC-1 $\alpha$. Cell Metab., 3(6):429-438.

http://dx.doi.org/10.1016/j.cmet.2006.04.013

Li, H.L., Huang, Y., Zhang, C.N., et al., 2006. Epigallocathechin-3 gallate inhibits cardiac hypertrophy through blocking reactive oxidative species-dependent and -independent signal pathways. Free Radic. Biol. Med., 40(10):1756-1775. http://dx.doi.org/10.1016/j.freeradbiomed.2006.01.005

Lindenmayer, G.E., Sordahl, L.A., Harigaya, S., et al., 1971. Some biochemical studies on subcellular systems isolated from fresh recipient human cardiac tissue obtained during transplantation. Am. J. Cardiol., 27(3):277-283.

http://dx.doi.org/10.1016/0002-9149(71)90303-1

Lombard, D.B., Alt, F.W., Cheng, H.L., et al., 2007. Mammalian Sir2 homolog SIRT3 regulates global mitochondrial lysine acetylation. Mol. Cell. Biol., 27(24): 8807-8814.

http://dx.doi.org/10.1128/MCB.01636-07

Lorenzen, J.M., Martino, F., Thum, T., 2012. Epigenetic modifications in cardiovascular disease. Basic Res. Cardiol., 107(2):245. $\mathrm{http} / / / \mathrm{dx}$. doi.org/10.1007/s00395-012-0245-9

Lüscher, T.F., 2015. Risk factors for and management of heart failure. Eur. Heart J., 36(34):2267-2269. http://dx.doi.org/10.1093/eurheartj/ehv348

Marzetti, E., Csiszar, A., Dutta, D., et al., 2013. Role of mitochondrial dysfunction and altered autophagy in cardiovascular aging and disease: from mechanisms to therapeutics. Am. J. Physiol. Heart Circ. Physiol., 305(4): H459-H476. http://dx.doi.org/10.1152/ajpheart.00936.2012

Morita, H., Seidman, J., Seidman, C.E., 2005. Genetic causes of human heart failure. J. Clin. Invest., 115(3):518-526. http://dx.doi.org/10.1172/JCI24351

Mozaffarian, D., Benjamin, E.J., Go, A.S., et al., 2016. Heart disease and stroke statistics-2016 update: a report from the American Heart Association. Circulation, 133(4): e38-e360. http://dx.doi.org/10.1161/CIR.0000000000000350

Murphy, E., Steenbergen, C., 2008. Mechanisms underlying acute protection from cardiac ischemia-reperfusion injury. Physiol. Rev., 88(2):581-609. http://dx.doi.org/10.1152/physrev.00024.2007

Ohtani, T., Mohammed, S.F., Yamamoto, K., et al., 2012. Diastolic stiffness as assessed by diastolic wall strain is associated with adverse remodelling and poor outcomes in heart failure with preserved ejection fraction. Eur. Heart J., 33(14):1742-1749. http://dx.doi.org/10.1093/eurheartj/ehs135

Olivetti, G., Abbi, R., Quaini, F., et al., 1997. Apoptosis in the failing human heart. N. Engl. J. Med., 336(16):1131-1141. http://dx.doi.org/10.1056/NEJM199704173361603

Onyango, P., Celic, I., McCaffery, J.M., et al., 2002. SIRT3, a human SIR2 homologue, is an NAD-dependent deacetylase localized to mitochondria. PNAS, 99(21): 13653-13658. http://dx.doi.org/10.1073/pnas.222538099

Pillai, V.B., Samant, S., Sundaresan, N.R., et al., 2015. Honokiol blocks and reverses cardiac hypertrophy in mice by activating mitochondrial Sirt3. Nat. Commun., 6:6656. http://dx.doi.org/10.1038/ncomms7656

Piper, H.M., Garcia-Dorado, D., Ovize, M., 1998. A fresh look at reperfusion injury. Cardiovasc. Res., 38(2):291-300. http://dx.doi.org/10.1016/S0008-6363(98)00033-9

Richter, M., Kostin, S., 2015. The failing human heart is characterized by decreased numbers of telocytes as result 
of apoptosis and altered extracellular matrix composition. J. Cell. Mol. Med., 19(11):2597-2606.

http://dx.doi.org/10.1111/jcmm.12664

Rose, G., Dato, S., Altomare, K., et al., 2003. Variability of the SIRT3 gene, human silent information regulator Sir2 homologue, and survivorship in the elderly. Exp. Gerontol., 38(10):1065-1070.

Schaper, J., Meiser, E., Stammler, G., 1985. Ultrastructural morphometric analysis of myocardium from dogs, rats, hamsters, mice, and from human hearts. Circ. Res., 56(3): 377-391. http://dx.doi.org/10.1161/01.RES.56.3.377

Scher, M.B., Vaquero, A., Reinberg, D., 2007. SirT3 is a nuclear $\mathrm{NAD}^{+}$-dependent histone deacetylase that translocates to the mitochondria upon cellular stress. Genes Dev., 21(8):920-928. http://dx.doi.org/10.1101/gad.1527307

Schwer, B., Verdin, E., 2008. Conserved metabolic regulatory functions of sirtuins. Cell Metab., 7(2):104-112. http://dx.doi.org/10.1016/j.cmet.2007.11.006

Smith, B.C., Settles, B., Hallows, W.C., et al., 2011. SIRT3 substrate specificity determined by peptide arrays and machine learning. ACS Chem. Biol., 6(2):146-157. http://dx.doi.org/10.1021/cb100218d

Someya, S., Yu, W., Hallows, W.C., et al., 2010. Sirt3 mediates reduction of oxidative damage and prevention of age-related hearing loss under caloric restriction. Cell, 143(5):802-812. http://dx.doi.org/10.1016/j.cell.2010.10.002

Sordahl, L.A., McCollum, W.B., Wood, W.G., et al., 1973. Mitochondria and sarcoplasmic reticulum function in cardiac hypertrophy and failure. Am. J. Physiol., 224(3): 497-502.

Spann, J.F., Buccino, R.A., Sonnenblick, E.H., et al., 1967. Contractile state of cardiac muscle obtained from cats with experimentally produced ventricular hypertrophy and heart failure. Circ. Res., 21(3):341-354. http://dx.doi.org/10.1161/01.RES.21.3.341

Stanley, W.C., Chandler, M.P., 2002. Energy metabolism in the normal and failing heart: potential for therapeutic interventions. Heart Fail. Rev., 7(2):115-130. http://dx.doi.org/10.1023/A:1015320423577

Sundaresan, N.R., Samant, S.A., Pillai, V.B., et al., 2008. SIRT3 is a stress-responsive deacetylase in cardiomyocytes that protects cells from stress-mediated cell death by deacetylation of Ku70. Mol. Cell. Biol., 28(20):63846401.

http://dx.doi.org/10.1128/MCB.00426-08

Sundaresan, N.R., Gupta, M., Kim, G., et al., 2009. Sirt3 blocks the cardiac hypertrophic response by augmenting Foxo3a-dependent antioxidant defense mechanisms in mice. J. Clin. Invest., 119(9):2758-2771. http://dx.doi.org/10.1172/JCI39162

Taegtmeyer, H., 1994. Energy metabolism of the heart: from basic concepts to clinical applications. Curr. Probl. Cardiol., 19(2):59-113. http://dx.doi.org/10.1016/0146-2806(94)90008-6

Tan, W.Q., Wang, K., Lv, D.Y., et al., 2008. Foxo3a inhibits cardiomyocyte hypertrophy through transactivating catalase. J. Biol. Chem., 283(44):29730-29739. http://dx.doi.org/10.1074/jbc.M805514200

Towbin, J.A., 2014. Inherited cardiomyopathies. Circ. J., 78(10):2347-2356. http://dx.doi.org/10.1253/circj.CJ-14-0893

Townsend, N., Nichols, M., Scarborough, P., et al., 2015. Cardiovascular disease in Europe-epidemiological update 2015. Eur. Heart J., 36(40):2696-2705. http://dx.doi.org/10.1093/eurheartj/ehv428

Tseng, A.H., Shieh, S.S., Wang, D.L., 2013. SIRT3 deacetylates FOXO3 to protect mitochondria against oxidative damage. Free Radic. Biol. Med., 63:222-234. http://dx.doi.org/10.1016/j.freeradbiomed.2013.05.002

van Empel, V.P., Bertrand, A.T., van Oort, R.J., et al., 2006. EUK-8, a superoxide dismutase and catalase mimetic, reduces cardiac oxidative stress and ameliorates pressure overload-induced heart failure in the harlequin mouse mutant. J. Am. Coll. Cardiol., 48(4):824-832. http://dx.doi.org/10.1016/j.jacc.2006.02.075

Velagaleti, R.S., Pencina, M.J., Murabito, J.M., et al., 2008. Long-term trends in the incidence of heart failure after myocardial infarction. Circulation, 118(20):2057-2062. http://dx.doi.org/10.1161/circulationaha.108.784215

Verdejo, H.E., del Campo, A., Troncoso, R., et al., 2012. Mitochondria, myocardial remodeling, and cardiovascular disease. Curr. Hypertens. Rep., 14(6):532-539. http://dx.doi.org/10.1007/s11906-012-0305-4

Wenzel, S., Rohde, C., Wingerning, S., et al., 2007. Lack of endothelial nitric oxide synthase-derived nitric oxide formation favors hypertrophy in adult ventricular cardiomyocytes. Hypertension, 49(1):193-200. http://dx.doi.org/10.1161/01.HYP.0000250468.02084.ce

Winnik, S., Auwerx, J., Sinclair, D.A., 2015. Protective effects of sirtuins in cardiovascular diseases: from bench to bedside. Eur. Heart J., 36(48):3404-3412.

http://dx.doi.org/10.1093/eurheartj/ehv290

Xia, W., Geng, K., 2016. A sirtuin activator and an antiinflammatory molecule-multifaceted roles of adjudin and its potential applications for aging-related diseases. Semin. Cell Dev. Biol., in press. http://dx.doi.org/10.1016/j.semcdb.2016.07.020

Yancy, C.W., Jessup, M., Bozkurt, B., et al., 2013. 2013 ACCF/AHA guideline for the management of heart failure: executive summary: a report of the American College of Cardiology Foundation/American Heart Association Task Force on Practice Guidelines. Circulation, 128(16): 1810-1852.

http://dx.doi.org/10.1161/CIR.0b013e31829e8807

Yang, X.J., Seto, E., 2007. HATs and HDACs: from structure, function and regulation to novel strategies for therapy and prevention. Oncogene, 26(37):5310-5318. http://dx.doi.org/10.1038/sj.onc. 1210599

Yue, Z., Ma, Y., You, J., et al., 2016. NMNAT3 is involved in 
the protective effect of SIRT3 in Ang II-induced cardiac hypertrophy. Exp. Cell Res., 347(2):261-273. http://dx.doi.org/10.1016/j.yexcr.2016.07.006

Zeller, T., Blankenberg, S., Diemert, P., 2012. Genomewide association studies in cardiovascular disease - an update 2011. Clin. Chem., 58(1):92-103. http://dx.doi.org/10.1373/clinchem.2011.170431

Zeng, H., Vaka, V.R., He, X., et al., 2015. High-fat diet induces cardiac remodelling and dysfunction: assessment of the role played by SIRT3 loss. J. Cell. Mol. Med., 19(8): 1847-1856. http://dx.doi.org/10.1111/jcmm.12556

Zhang, L., Zhang, Z., Guo, H., et al., 2008. $\mathrm{Na}^{+} / \mathrm{K}^{+}$-ATPasemediated signal transduction and $\mathrm{Na}^{+} / \mathrm{K}^{+}$-ATPase regulation. Fundam. Clin. Pharmacol., 22(6):615-621. http://dx.doi.org/10.1111/j.1472-8206.2008.00620.x

Zhang, Y., Huo, Y., 2011. Early reperfusion strategy for acute myocardial infarction: a need for clinical implementation. J. Zhejiang Univ.-Sci. B (Biomed. \& Biotechnol.), 12(8): 629-632. http://dx.doi.org/10.1631/jzus.B1101010

Zou, X.J., Yang, L., Yao, S.L., 2008. Propofol depresses angiotensin II-induced cardiomyocyte hypertrophy in vitro. Exp. Biol. Med. (Maywood), 233(2):200-208. http://dx.doi.org/10.3181/0707-RM-206

\section{中文概要}

题 目: SIRT3 在心衰中的作用：从基础到临床

概 要: 心血管疾病是全世界范围内导致人口死亡率的首 要因素, 而心力衰竭是绝大多数心血管疾病的共 同最终通路。尽管近年来对于心血管疾病的治疗 取得了巨大的进展，但心衰的发病率仍在增加。 良好的预后结果被认为是来自于积极的预防而 非额外的治疗。因此, 对于心衰更加合理的做法 应是预防心血管疾病或其他临床综合症的发展。 大多数心衰是由于收缩功能丧失、心肌肥厚或重 塑和心肌缺血性损伤引起的。Sirtuins 是一种烟 酰胺腺嘌呤二核苷酸 (NAD) 依赖的蛋白去乙酰 化酶, 它的底物包括从代谢相关蛋白到应激抵抗 相关蛋白的多种生物过程中。近年来, 许多研究 已经确证了其心脏保护作用, 并且一些药物或小 分子化合物已被用于提高其表达或活性。在本综 述中, 我们将概括一下 SIRT3 在机械压力超负荷 或者刺激剂诱导的心肌肥厚以及心肌细胞缺血 性损伤中的作用。最后, 我们还将介绍一下 SIRT3 激动剂在预防心肌肥厚和缺血再灌注损 伤中的应用。

关键词: SIRT3; 心力衰竭; 心肌肥厚; 缺血再灌注 